\title{
Clinical Manifestation of Congenital Aniridia in Indonesia
}

\author{
Irawati Irfani ${ }^{1,2 *}$, Levandi Mulja1,2, Sesy Caesarya ${ }^{1,2}$, Primawita Oktarima ${ }^{1,2}$, Mayasari Wahyu ${ }^{1,2}$, \\ Feti K. Memed1,2
}

${ }^{1}$ Ophthalmology Department, Faculty of Medicine Universitas Padjadjaran, Bandung, Indonesia

${ }^{2}$ Cicendo National Eye Hospital, Bandung, Indonesia

Email: *irawati.irfani@unpad.ac.id

How to cite this paper: Irfani, I., Mulja, L., Caesarya, S., Oktarima, P., Wahyu, M. and Memed, F.K. (2020) Clinical Manifestation of Congenital Aniridia in Indonesia. Open Journal of Ophthalmology, 10, 133-141. https://doi.org/10.4236/ojoph.2020.102015

Received: April 11, 2020

Accepted: May 8, 2020

Published: May 11, 2020

Copyright $\odot 2020$ by author(s) and Scientific Research Publishing Inc. This work is licensed under the Creative Commons Attribution International License (CC BY 4.0). http://creativecommons.org/licenses/by/4.0/

\begin{abstract}
Background: Congenital aniridia is a rare, panophthalmic disorder that can cause vision loss. Knowledge of aniridia as an isolated ocular abnormality or as a part of systemic abnormalities is important. Management of congenital aniridia should be carried out comprehensively based on it. Objective: To describe clinical features and management of congenital aniridia in a top referral eye hospital in Indonesia. Methods: A retrospective study involving 43 eyes of 22 children (younger than 18 years) diagnosed with congenital aniridia from 2013 to 2018. A detailed history was taken and a complete ophthalmic examination and a systemic examination were performed as required. Clinical characteristics associated with ocular and systemic manifestation and its management were noted. Results: Mean age of patients was $7.6 \pm 5.2$ years (range $0-17$ years). Most cases were female (55\%) and sporadic (77\%). Twenty-one (96\%) patients had bilateral involvement at presentation. Foveal hypoplasia was found in 36 eyes $(84 \%)$, followed by cataract in 26 eyes (61\%) and secondary glaucoma in 13 eyes (30\%). Nine patients (43\%) with cataract had cataract surgery performed. Only 1 patient (5\%) with secondary glaucoma underwent filtration surgery. All patients had moderate to severe visual impairment and low vision aid was considered. Regarding its systemic manifestation, none of the patients was diagnosed with an abnormality in the abdomen. Conclusion: There were various ocular features associated with congenital aniridia. Understanding the clinical characteristic and its management could improve the quality of vision in aniridia patients.
\end{abstract}

\section{Keywords}

Congenital Aniridia, Clinical Features, Management 


\section{Introduction}

Aniridia is a disorder categorized as rare or infrequently occurring by the $\mathrm{Na}$ tional Organization for Rare Disorders, with an incidence of one in 50.000 100.000 live births [1] [2]. Epidemiological data for congenital aniridia are limited, as most studies of the condition are case reports. An observational study was conducted in South Korea with 31 congenital aniridia patients over a 10 years period [3]. However, no studies regarding congenital aniridia in Indonesia have been published.

Aniridia is described as partial or total absence of iris. For congenital aniridia, mutations in the following genes have been reported; PAX6, FOXC1, PITX2, CYP1B1, FOXD3 and TRIM44 [2]. Based on genes associated, aniridia can be categorized into two groups: classic aniridia, associated with mutations in genes PAX6, and aniridia-like, associated with mutations in genes other than PAX6. Ocular findings for this condition include partial or near-total absence of iris, cataract, aniridia-associated keratopathy, glaucoma, foveal hypoplasia, optic disk hypoplasia, and nystagmus [2] [4]. Congenital aniridia has varied clinical and genetic characteristics; two-thirds of cases are inherited autosomal dominant, and the remain are sporadic. Pathological conditions of aniridia are not restricted to iris abnormalities, and the disease can be bilateral and panocular, causing severe visual impairment. Apart from its ocular disorder, congenital aniridia is also associated with systemic disorders such as Wilms tumor-Aniridia-Genitourinary anomaly-Mental Retardation syndrome. The management of patients with congenital aniridia is thus complex and multidisciplinary [4] [5] [6] [7]. The purpose of the present study was to describe the clinical features and management of congenital aniridia in the Cicendo National Eye Hospital (CNEH), which is the top referral eye hospital in Indonesia.

\section{Materials and Methods}

This retrospective descriptive study was utilizing the medical records of patients diagnosed with congenital aniridia in 2013-2018. The study adhered to the tenets of the Declaration of Helsinki and was approved by the Institutional Review Board (IRB) University of Padjadjaran. Patient informed consent was not required by the IRB because the data were collected retrospectively, and patient data were de-identified to protect patient privacy. All new patients under 18 years of age and diagnosed with congenital aniridia by consultants in the pediatric ophthalmology unit were included. Patients with a history of ocular trauma and previous eye surgery were excluded. Age, sex, family history, laterality, visual acuity, intraocular pressure, other ocular abnormalities, systemic manifestations, and management were recorded.

\section{Results}

Congenital aniridia was observed in 43 eyes of 22 pediatric patients. Patient characteristics are shown in Table 1 . The mean patient age in this study was 7.6 
years (range: 0 - 17 years), with 55\% of cases in females. Most of the patients (77\%) did not have a family history, and bilateral involvement was present in $95 \%$ of cases.

\subsection{Clinical Features of Congenital Aniridia}

The clinical features of congenital aniridia are shown in Table 2. The most common ocular abnormalities associated with aniridia were nystagmus ( $98 \%$ of eyes), foveal hypoplasia ( $84 \%$ of eyes), and cataract ( $60 \%$ of eyes). The complication of secondary glaucoma occurred in $30 \%$ of eyes.

All patients were referred to a pediatrician, and abdominal ultrasonography (USG) examinations were recommended. However, only two patients underwent abdominal USG, and the findings were unremarkable. One patient was diagnosed with cerebral palsy.

Table 1. Characteristics of congenital aniridia patients.

\begin{tabular}{cc}
\hline Characteristics & $\begin{array}{c}\text { Number/(\%) } \\
(\mathbf{n}=\mathbf{4 3} \text { eyes/22 patients })\end{array}$ \\
\hline Age & $7.6 \pm 5.2$ \\
$($ mean [years] $)$ & $0-17$ \\
$($ range [years] & \\
Sex $(\mathbf{n}=\mathbf{2 2})$ & $10(45)$ \\
Male & $12(55)$ \\
Female & \\
Family history & $5(23)$ \\
Familial & $17(77)$ \\
Sporadic & \\
Laterality (n $=43)$ & $1(5)$ \\
Unilateral & $21(95)$ \\
Bilateral &
\end{tabular}

Table 2. Clinical features associated with congenital aniridia.

\begin{tabular}{ccc}
\hline Ocular abnormalities & $\begin{array}{c}\text { Number/(\%) } \\
(\mathrm{n}=\mathbf{2 2} \text { patients })\end{array}$ & $\begin{array}{c}\text { Number/(\%) } \\
(\mathrm{n}=\mathbf{4 3} \text { eyes })\end{array}$ \\
\hline Nystagmus & $21(95)$ & $42(98)$ \\
Secondary glaucoma & $8(36)$ & $13(30)$ \\
Microcornea & $5(23)$ & $10(23)$ \\
Keratopathy & $5(23)$ & $8(19)$ \\
Cataract & $13(59)$ & $26(60)$ \\
Subluxated lens & $4(18)$ & $7(16)$ \\
Microspherophakia & $3(14)$ & $6(14)$ \\
Lentiglobus & $1(5)$ & $1(2)$ \\
Lens coloboma & $1(5)$ & $1(2)$ \\
Foveal hypoplasia & $21(95)$ & $36(84)^{*}$ \\
\hline
\end{tabular}

${ }^{\star}$ The posterior segment could not be evaluated in some subjects due to media opacity. 


\subsection{Management and Outcome Treatment in Congenital Aniridia}

The types of management for congenital aniridia and clinical outcomes are shown in Table 3. Almost all of the patients were given low vision aids to improve their quality of vision. Cataracts, as seen in Figure 1, were common complication and occurred bilaterally in 13 patients (59\%). Cataract surgeries were performed in 18 cataractous eyes (42\%), resulting in 14 aphakic eyes and four pseudophakic eyes as displayed in Figure 2. All patients with cataract were given refractive error correction, and the best-corrected visual acuity (BCVA) is shown in Table 3.

In this study, eight patients had secondary glaucoma, but only 13 eyes had an elevated intraocular pressure (IOP). Mean IOP among eyes with secondary glaucoma was $33.75 \pm 12.5 \mathrm{mmHg}$. Six of 13 eyes $(46 \%)$ were recorded as having a glaucomatous optic nerve. Eleven eyes (85\%) received antiglaucoma medication, but three patients did not attend follow-up visits. The mean IOP after treatment was $22.4 \pm 5.9 \mathrm{mmHg}$ with a mean follow-up duration of $4.1 \pm 1$ month. One patient had failed in medication and received filtration surgery, as shown in a subject no. 4 in Table 3.

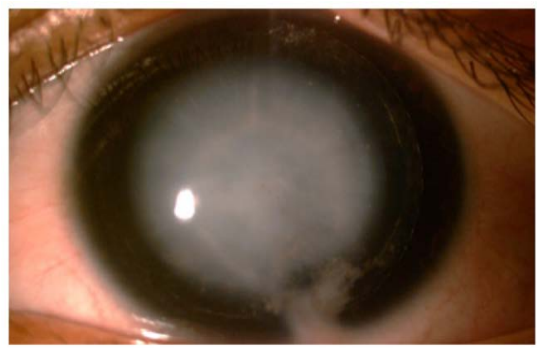

(a)

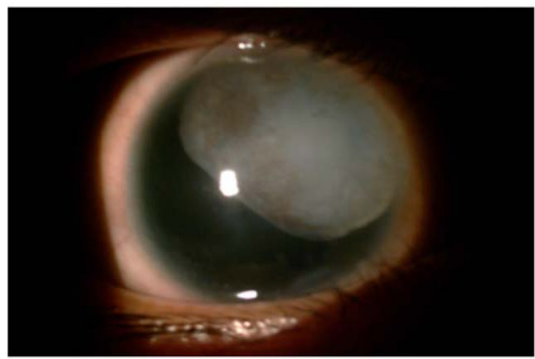

(b)

Figure 1. (a) Total cataract in aniridia; (b) subluxated cataract in aniridia.

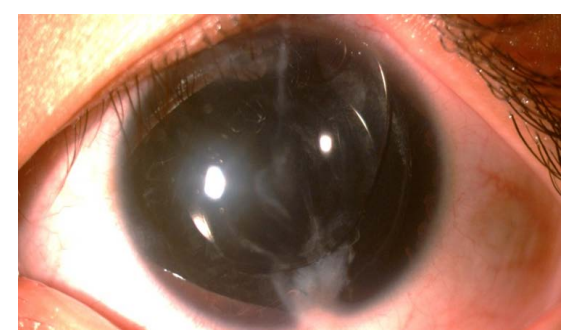

Figure 2. Pseudophakia in an aniridia eye. 
Table 3. Management of congenital aniridia patient.

\begin{tabular}{|c|c|c|c|c|c|c|c|c|c|c|c|}
\hline \multirow{2}{*}{ Subject } & \multirow{2}{*}{$\begin{array}{c}\text { Age } \\
\text { (years) }\end{array}$} & \multicolumn{2}{|c|}{ UCVA } & \multicolumn{2}{|c|}{ BCVA } & \multicolumn{2}{|c|}{ Initial IOP (mmHg) } & \multicolumn{2}{|c|}{ IOP post-treatment $(\mathrm{mmHg})$} & \multirow{2}{*}{$\begin{array}{l}\text { Non-surgical } \\
\text { management }\end{array}$} & \multirow{2}{*}{$\begin{array}{c}\text { Surgical } \\
\text { management }\end{array}$} \\
\hline & & OD & Os & OD & Os & OD & Os & OD & OS & & \\
\hline 1 & 8 & $2 / 60$ & $2 / 60$ & $4 / 32$ & $4 / 40$ & $\operatorname{dig} \mathrm{N}$ & $\operatorname{dig} \mathrm{N}$ & N/A & N/A & GL, LVA & \\
\hline 2 & 7 & CFFC & CFFC & 0.2 & 0.2 & 17 & 20 & N/A & N/A & GL, LVA & $\mathrm{AI}+\mathrm{PPC}$ ODS \\
\hline 3 & 7 & 0.1 & 0.1 & 0.1 & 0.1 & $\operatorname{dig} \mathrm{N}$ & $\operatorname{dig} N$ & N/A & $\mathrm{N} / \mathrm{A}$ & GL, LVA & \\
\hline 4 & 8 & $2 / 60$ & $2 / 60$ & 0.1 & 0.1 & 40 & 38 & 12 & 14 & GL, LVA, GM & trabeculectomy $+5 \mathrm{FU}$ \\
\hline 5 & 12 & $1 / 300$ & $1 / 60$ & CFFC & 0.1 & 21.5 & 27.9 & 12 & 15 & GL, LVA, GM & $\mathrm{AI}+\mathrm{PPC} \mathrm{OD}$ \\
\hline 6 & 7 & 0.1 & 0.1 & 0.2 & 0.1 & 9 & 10 & N/A & N/A & GL, LVA & \\
\hline 7 & 13 & $1 / 300$ & CFFC & N/A & N/A & 42 & Over & N/A & N/A & GM & \\
\hline 8 & 6 & $2 / 60$ & $2 / 60$ & 0.125 & 0.1 & $\operatorname{dig} \mathrm{N}$ & $\operatorname{dig} \mathrm{N}$ & 14 & 14 & GL, LVA & $\mathrm{AI}+\mathrm{PPC}$ ODS \\
\hline 9 & 3 & 0.08 & 0.08 & N/A & N/A & 23 & 16 & $\mathrm{~N} / \mathrm{A}$ & N/A & GM & \\
\hline 10 & 17 & 0.2 & $1 / 300$ & $4 / 10$ & $4 / 10$ & 22 & 64 & 17 & 42 & GL, LVA, GM & \\
\hline 11 & 0 & FTO & FTO & N/A & $\mathrm{N} / \mathrm{A}$ & 18 & 20 & N/A & N/A & Conservative & \\
\hline 12 & 15 & NLP & $1 / 60$ & NLP & 0.15 & 23.5 & 13.5 & $\operatorname{dig} \mathrm{N}$ & $\operatorname{dig} N$ & GL, LVA, GM & PPL ODS \\
\hline 13 & 11 & 0.1 & $1 / 300$ & 0.2 & 0.05 & 10 & 7 & $\operatorname{dig} \mathrm{N}$ & $\operatorname{dig} \mathrm{N}$ & GL, LVA & $\mathrm{AI}+\mathrm{PPC}$ OS \\
\hline 14 & 0 & FTL & FTL & N/A & N/A & 6 & 7 & N/A & N/A & conservative & \\
\hline 15 & 7 & 0.1 & 0.1 & 0.1 & 0.1 & 14 & 12 & $\operatorname{dig} \mathrm{N}$ & $\operatorname{dig} N$ & GL, LVA & \\
\hline 16 & 10 & 0.125 & 0.16 & 0.125 & 0.16 & 15 & 15 & N/A & N/A & GL, LVA & \\
\hline 17 & 10 & CFFC & 0.125 & 0.1 & 0.2 & 42 & 36 & N/A & $\mathrm{N} / \mathrm{A}$ & GL, GM & PPL ODS \\
\hline 18 & 0 & FTL & FTL & N/A & $\mathrm{N} / \mathrm{A}$ & 7 & 7 & N/A & $\mathrm{N} / \mathrm{A}$ & conservative & \\
\hline 19 & 4 & $1 / 60$ & $1 / 60$ & $3 / 15$ & $3 / 30$ & $\operatorname{dig} \mathrm{N}$ & $\operatorname{dig} \mathrm{N}$ & $\operatorname{dig} \mathrm{N}$ & $\operatorname{dig} \mathrm{N}$ & GL & $\mathrm{AI}+\mathrm{PPC}$ ODS \\
\hline 20 & 0 & FTO & FTO & N/A & N/A & $\operatorname{dig} N$ & $\operatorname{dig} \mathrm{N}$ & N/A & $\mathrm{N} / \mathrm{A}$ & conservative & \\
\hline 21 & 17 & $1 / 300$ & 0.15 & $\mathrm{~N} / \mathrm{A}$ & 0.15 & 16 & 17 & $\operatorname{dig} \mathrm{N}$ & $\operatorname{dig} \mathrm{N}$ & GL & $\mathrm{AI}+\mathrm{IOL}$ ODS \\
\hline 22 & 6 & 0.05 & 0.05 & $2 / 24$ & $2 / 30$ & 12 & 24 & $\operatorname{dig} \mathrm{N}$ & $\operatorname{dig} \mathrm{N}$ & GL, GM & $\mathrm{AI}+\mathrm{PPC}+\mathrm{IOL} \mathrm{ODS}$ \\
\hline
\end{tabular}

$\mathrm{UCVA}=$ Uncorrected visual acuity; BCVA = Best corrected visual acuity; IOP = Intraocular pressure; Dig = Digital palpation of IOP; CFFC = Closed faced finger counting; FTO = Follow the object; FTL = Follow the light; NLP = No light perception; GL = glasses; LVA = Low vision aid (magnifier, telescope); $\mathrm{GM}=$ Antiglaucoma medication; $\mathrm{AI}=$ Aspiration-irrigation; $\mathrm{PPL}=$ Pars plana lensectomy; $\mathrm{PPC}=$ Primary posterior capsulotomy; $\mathrm{IOL}=$ intraocular lens; N/A = Not available.

\section{Discussion}

Congenital aniridia is generally a bilateral condition. In the present study, one patient had unilateral aniridia and Peter's anomaly in his fellow eye. Sawada et al. reported a similar unilateral case. The hypothesis is that the PAX6 gene mutation can cause a differential phenotype in the fellow eyes of the same individual [4] [8]-[13].

In the present study, congenital aniridia was present equally in both sexes. Consistently, previous studies failed to identify any association between gender or ethnicity and the occurrence of aniridia [5] [14] [15] [16]. Congenital aniridia is ordinarily a hereditary condition, but in this study, aniridia was sporadic in $77 \%$ of cases. However, this finding needs to be further investigated, as it was based only on patient interviews [5] [14] [15] [16]. 
The most common ocular abnormalities associated with aniridia were nystagmus (98\% eyes), foveal hypoplasia ( $84 \%$ eyes), and cataract (60\% eyes). Nystagmus was caused by foveal hypoplasia. In six eyes, the fovea could not be assessed due to cataract. In the present study, foveal hypoplasia was diagnosed through funduscopic examination and characterized by loss of foveal reflex. A study by Samant et al. identified that foveal hypoplasia occurred in $90 \%$ of subjects with congenital aniridia, and another study by Netland found similar results (84\%). Although the present study was consistent with these prior findings, there is currently no explanation of the etiology of foveal hypoplasia in aniridia. Some studies suggest that foveal pit formation involves several genes in addition to the PAX6 gene [2] [4] [6] [17] [18] [19] [20].

Cataracts were present in approximately $60 \%$ of eyes. Prior studies identified a cataract incidence of 50\% - 90\% in aniridia patients [7] [21] [22]. Cataracts can occur at any time during life but generally first appear during the first two decades of life. In the present study, cataracts were found in much younger patients, predominately in the first decade of life. Lens abnormalities, including subluxation of the lens (16\%), microspherophakia (14\%), lentiglobus (2\%), and coloboma of the lens (2\%) were also detected. This result was consistent with a study by Singh et al., which identified that the most common lens abnormalities in aniridia are cataracts $(38.5 \%)$, subluxation of the lens $(22.3 \%)$, microspherophakia (2.3\%), lens coloboma (2.3\%), and lenticonus (0.8\%) [7] [21] [22].

In the present study, cataract surgeries were performed in 18 of 20 eyes with cataract. The type of surgery was either aspiration of the lens with the anterior approach or pars plana lensectomy. In all patients who received anterior approach lens aspiration, primary posterior capsulotomy (PPC) was performed. Fourteen eyes were left aphakic because of the unstable zonule of Zinn and a corneal diameter of less than $10 \mathrm{~mm}$. Four eyes received a single-piece Neo-eye ${ }^{\circledR}$ intraocular lens (IOL) implant in the bag. All 18 treated cataracted eyes had improved postoperative corrected visual acuity, as shown in Table 3 [2] [3] [6] [23] [24].

Another common complication of aniridia is secondary glaucoma. Secondary glaucoma occurs in 50\% - 75\% of cases [2] [6] [23] [24]. The mechanism of glaucoma in aniridia is related to an abnormal anterior chamber angle. Although congenital aniridia is generally a bilateral condition, some pathological features, such as secondary glaucoma, are frequently unilateral. Eight patients had secondary glaucoma, but only 13 eyes (30\%) had elevated intraocular pressure (IOP). Eleven eyes with secondary glaucoma received antiglaucoma medication, but three patients did not attend follow-up visits. Landsend et al. demonstrated that topical antiglaucoma medication is the preferred treatment for glaucoma secondary to aniridia [1]. A study by Netland et al. showed that no significant difference $(p=0.152)$ in the mean of medications in subjects with aniridia and glaucoma who had been treated with surgery $(2.2 \pm 1.5)$ compared with those who had not been treated with surgery $(1.6 \pm 0.99)$ [4]. This present study also identified decreased mean IOP after antiglaucoma treatment $(22.4 \pm 5.9 \mathrm{mmHg}$ from $33.75 \pm 12.5 \mathrm{mmHg}$ ) in $4.1 \pm 1$ months of follow-up. Although mean IOP 
tended to decrease, long-term follow-ups are needed to evaluate the response to antiglaucoma medications.

If pharmacological treatment of glaucoma fails, surgical procedures can be considered. However, Toledo et al. suggested that none of the available surgical techniques have been proven to be effective in the treatment of secondary glaucoma in aniridia patients [24]. By contrast, Wiggin et al. identified that trabeculectomy is recommended as an initial therapy in aniridia patients with uncontrolled glaucoma, which had a relatively low success rate of 9\% - 17\% [25]. Anti-metabolite use was evaluated in several studies. Okada et al. found that mitomycin C increases the success rate of trabeculectomy in aniridia patients [26]. However, another study found that even with concurrent mitomycin C treatment, the failure rate of trabeculectomy was more than $60 \%$ [1] [6] [23] [24] [25]. In the present study, one patient failed to respond to medication treatment in both eyes and received trabeculectomy + mitomycin C. Antiglaucoma treatments were continued after surgery, but IOP remained high $(>30 \mathrm{mmHg})$. In order to reach the lower IOP, secondary trabeculectomy $+5 \mathrm{FU}$ was performed in both eyes. Four months after the second surgery, a lower target IOP $(<20 \mathrm{mmHg})$ was attained with the addition of two types of topical antiglaucoma medications.

Management of congenital aniridia is generally symptomatic, and observation is needed to prevent further complications. Photochromic eyeglasses are a potential option to reduce glare. Low vision aids are mandatory to improve the quality of vision in aniridia patients [2] [3] [4] [24].

This study has several limitations that should be acknowledged. First, the study was retrospective in design and based on medical records. Further, there were variations in the method of IOP measurement, and family history was based only on patient and parent interviews. Some patients did not attend follow-up visits, so some information was missing in several patients.

\section{Conclusion}

Congenital aniridia is a panocular condition that has various ocular features and systemic manifestations. Management is generally symptomatic and associated with the specific ocular manifestations. Systemic examinations, including the central nervous system and genitourinary system, should be routinely performed, and child development should be routinely monitored in all aniridia patients. Understanding the clinical characteristics and management of aniridia may improve the quality of vision in aniridia patients.

\section{Conflicts of Interest}

The authors declare no conflicts of interest regarding the publication of this paper.

\section{References}

[1] Landsend, E.S., Utheim, A., Pedersen, H.R., et al. (2018) The Genetics of Congenital Aniridia-A Guide for the Ophthalmologist. Survey of Ophthalmology, 63, 105-113. https://doi.org/10.1016/j.survophthal.2017.09.004 
[2] Samant, M., Chauchan, B.K., Lathrop, K.L. and Nischal, K.K. (2016) Congenital Aniridia: Etiology, Manifestation and Management. Expert Review of Ophthalmology, 11, 135-144. https://doi.org/10.1586/17469899.2016.1152182

[3] Park, S.H., Park, Y.G., Lee, M.Y. and Kim, M.S. (2010) Clinical Features of Korean Patients with Congenital Aniridia. Korean Journal of Ophthalmology, 24, 291-296. https://doi.org/10.3341/kjo.2010.24.5.291

[4] Calvao-Pires, P., Santos-silva, R., Falca-Reis, F. and Rocha-Sousa, A. (2014) Congenital Aniridia: Clinic, Genetics, Therapeutics, and Prognosis. International Scholarly Research Notices, 2014, Article ID: 305350. https://doi.org/10.1155/2014/305350

[5] Netland, P.A., Scott, M.L., Boyle, J.W. and Lauderdale, J.D. (2011) Ocular and Systemic Findings in a Survey of Aniridia Subjects. Journal of AAPOS, 15, 562-566. https://doi.org/10.1016/j.jaapos.2011.07.009

[6] Hingorani, M., Hanson, I. and Van Heningen, V. (2012) Aniridia. European Journal of Human Genetics, 20, 1011-1017. https://doi.org/10.1038/ejhg.2012.100

[7] Singh, B., Mohamed, A., Chaurasia, S., et al. (2014) Clinical Manifestation of Congenital Aniridia. Journal of Pediatric Ophthalmology \& Strabismus, 51, 59-62. https://doi.org/10.3928/01913913-20131223-01

[8] Sawada, M., Sato, M., Hikoya, A., et al. (2011) A Case of Aniridia with Unilateral Peters Anomaly. Journal of AAPOS, 15, 104-106. https://doi.org/10.1016/j.jaapos.2010.11.006

[9] Bobilev, A.M., McDougal, M.E., Taylor, W.L., et al. (2016) Assesment of PAX6 Alleles in 66 Families with Aniridia. Clinical Genetics, 89, 669-677. https://doi.org/10.1111/cge.12708

[10] Lim, H.T., Seo, E.J., Kim, G.H., et al. (2012) Comparison between Aniridia with and without PAX6 Mutations: Clinical and Molecular Analysis in 14 Korean Patients with Aniridia. Ophthalmology, 119, 1258-1264. https://doi.org/10.1016/j.ophtha.2011.12.010

[11] Sannan, N.S., Gregory-Evans, C.Y., Lyons, C.J., et al. (2017) Correlation of Novel PAX6 Gene Abnormalities in Aniridia and Clinical Presentation. Canadian Journal of Ophthalmology, 52, 570-577. https://doi.org/10.1016/j.jcjo.2017.04.006

[12] Palayil, I., Priya, S.G., Sivan, N.V., et al. (2018) Identification of Novel Frameshift Mutation in PAX6 Gene and the Clinical Management in an Asian Indian Aniridia Family. Indian Journal of Ophthalmology, 66, 229-232.

[13] Lee, N.Y., Lee, Y.E., Mok, J., Kim, M. and Park, S.H. (2013) Three Cases with Unusual Ophthalmic Phenotypes of Congenital Aniridia. Canadian Journal of Ophthalmology, 48, 340-342. https://doi.org/10.1016/j.jcjo.2013.02.009

[14] Blanco-Kelly, F., Palomares, M., Vallespin, E., et al. (2017) Improving Molecular Diagnosis of Aniridia and WAGR Syndrome Using Customized Targeted Array-Based CGH. PLOS ONE, 12, e0172363.

[15] Adeoti, C.O., Afolabi, A.A., Ashaye, A.O. and Adeoye, A.O. (2010) Bilateral Sporadic Aniridia: Review of Management. Clinical Ophthalmology, 4, 1085-1089. https://doi.org/10.2147/OPTH.S11905

[16] Kelly, F.B., Villaverde-Montero, C., Lorda-Sanchez, I., et al. (2013) Guidelines for Genetic Study of Aniridia. Archivos de la Sociedad Española de Oftalmología, 88, 145-152. https://doi.org/10.1016/j.oftale.2012.07.004

[17] Yang, H., Yu, T., Sun, C., et al. (2011) Spectra-Domain Optical Coherence Tomography in Patients with Congenital Nystagmus. International Journal of Ophthalmology, 4, 627-630. 
[18] Cronin, T.H., Hertle, R.W., Ishikawa, H. and Schuman, J.S. (2009) Spectral Domain Optical Coherence Tomography for Detection of Foveal Morphology in Patients with Nystagmus. Journal of AAPOS, 13, 563-566.

https://doi.org/10.1016/j.jaapos.2009.09.019

[19] Thomas, M.G., Kumar, A., Mohammad, S., et al. (2011) Structural Grading of Foveal Hypoplasia Using Spectral-Domain Optical Coherence Tomography. Ophthalmology, 118, 1653-1660. https://doi.org/10.1016/j.ophtha.2011.01.028

[20] McCulley, T.J., Mayer, K., Dahrd, K., Simpson, J. and Holland, E.J. (2005) Aniridia and Optic Nerve Hypoplasia. Eye, 19, 762-764. https://doi.org/10.1038/sj.eye.6701642

[21] Wang, J.D., Zhang, J.S., Xiong, Y., et al. (2017) Congenital Aniridia with Cataract: Case Series. BMC Ophthalmology, 17, 115-120.

https://doi.org/10.1186/s12886-017-0503-6

[22] Lee, H., Khan, R. and O'Keefe, M. (2008) Aniridia: Current Pathology and Management. Acta Ophthalmologica, 86, 708-715. https://doi.org/10.1111/j.1755-3768.2008.01427.x

[23] Angmo, D., Jha, B. and Panda, A. (2011) Congenital Aniridia. Journal of Current Glaucoma Practice, 5, 1-13.

[24] Toledo, J.A., Gris, O., Santoja, J. and Teus, M.A. (2009) Spanish Guidelines for the Management of Congenital Aniridia. Spanish Aniridia Association, Salamanca.

[25] Wiggins, R.E., et al. (1992) The Results of Glaucoma Surgery in Aniridia. Archives of Ophthalmology, 110, 503-505. https://doi.org/10.1001/archopht.1992.01080160081036

[26] Okada, K., Mishima, H.K., Masumoto, M., et al. (2000) Hiroshima. Journal of Medical Sciences, 49, 135-138. https://doi.org/10.1108/00242530010317723 